\title{
Elementos y PERSPECTIVAS PARA EL ESTUDIO DEL ANAS COMO FRONTERA EN LA ANTIGÜEDAD: FUENTES CLÁSICAS, REGISTRO ARQUEOLÓGICO Y EPIGRAFÍA*
}

\section{Elements and perspectives for the study of Anas as a boundary in Antiquity: Classical Sources, Archaeological Record, and Epigraphy}

\author{
Pedro Albuquerque \\ FCT, Uniarq (Faculdade de Letras, Universidade de Lisboa) \\ Departamento de Prehistoria y Arqueología de la Universidad de Sevilla \\ Carlos Pereira \\ FCT, Uniarq (Faculdade de Letras, Universidade de Lisboa) \\ Museo de Cáceres \\ Sílvia Teixeira \\ FCT, Uniarq (Faculdade de Letras, Universidade de Lisboa)
}

\begin{tabular}{ll}
\hline Recibido: $15 / 01 / 2018$ & Aceptado: $31 / 05 / 2018$ \\
Revisado: $16 / 04 / 2018$ & Publicado: 29/06/2018
\end{tabular}

Resumen

Se plantean algunas cuestiones sobre la construcción de fronteras y límites en el contexto de la Cuenca Baja del Guadiana entre finales del siglo III a.C. y el siglo I d.C., y sobre los problemas de análisis de las fuentes clásicas (Polibio, Artemidoro, Estrabón, Mela, Plinio, etc.), especialmente cuando mencionan el río como marcador territorial. La imagen transmitida por estas fuentes no se refleja en el registro arqueológico y epigráfico: desde esta perspectiva, los datos revelan la posible formación de realidades multiculturales que caracterizan los espacios fronterizos, especialmente, en oppida como Myrtilis. Este estudio requiere una metodología comparativa que puede llevar a una mejor comprensión de los procesos de formación de fronteras territoriales y simbólicas en el Bajo Guadiana entre Baesuris (Castro Marim) y Myrtilis (Mértola).

Palabras Clave

Fronteras; Límites; Guadiana; Periodo romano; Epigrafía.

\section{ABSTRACT}

The aim of this paper is to present some questions about the construction of boundaries in the particular case of the Low Guadiana Valley between the end of 3rd Century $\mathrm{BC}$ and the $1^{\text {st }}$ Century $\mathrm{AD}$, as well as the problems associated with the analysis of the classical texts (Polybius, Artemidorus, Strabo, Mela, Pliny the Elder, etc.), especially when they use the river as a territorial marker. The image transmitted by these sources does not have a clear reflection on the epigraphical and archaeological record: in this perspective, the data reveal the possible formation of multicultural realities which characterizes the frontier spaces, especially in oppida like Myrtilis. This study requires a comparative methodology that should lead us to a better understanding of the processes of the formation of territorial and symbolic boundaries along the Low Guadiana Valley between Baesuris (Castro Marim) and Myrtilis (Mértola).

\section{KEY WORDS}

Boundaries; limits; Guadiana; Roman Period; Epigraphy.

* El presente trabajo se elaboró en el marco del proyecto O Baixo e Médio Guadiana (sécs. VIII a.C. - I d.C.): Percursos de uma fronteira (ANA-lise/ ANA-lisis), financiado por la Fundação para a Ciência e Tecnologia (FCT), con la referencia SFRH/BPD/110188/2015.

email:albuquerque@us.es 


\section{COMENTARIOS PREVIOS}

"Estoy convencido de que, si se trata de lugares conocidos, la mención de los nombres ayuda no poco a la memoria. Pero si se trata de lugares desconocidos, su mención desnuda equivale a la pronunciación de palabras sin significado, que penetran en el oído, pero no hallan soporte en la mente: no se puede relacionar lo dicho con algo conocido, y la exposición resulta confusa e incomprensible. Por lo cual hay que presentar algún método que posibilite a los que hablan de lugares desconocidos llevar a sus oyentes, en la medida de lo posible, a nociones verdaderas y conocidas."

$$
\text { Plb., 3,36,3-4 (Trad. Balasch Recort) }
$$

Este fragmento de un excurso geográfico de Polibio $(3,36-38)$ es un testimonio interesantísimo de la representación y conocimiento de los territorios mencionados por un autor y transmitidos a receptores que no los conocen con la misma profundidad (cf. Cruz, 2006, 79). Respectando dicho método, este historiador añade su concepción de los grandes espacios geográficos (Ásia, África y Europa) y señala sus límites en el Tanais (i.e., Don), el Nilo y las Columnas de Heracles, transmitiendo a sus lectores u oyentes una visión menos "oscura" y general de las realidades que, a continuación, describe. Sin embargo, en lo que respecta a la Península Ibérica, su texto refleja los nuevos conocimientos sobre los territorios a occidente de las Columnas de Heracles.

Este pasaje nos informa sobre otros problemas que estos textos plantean, sobre todo cuando se trata de discursos que pretendían describir realidades que, como la Península Ibérica, eran desconocidas para los receptores y poco conocidas por estos autores (cf. García Fernández, 2003, 58-59). Los ríos y otros elementos geográficos destacables eran, en este sentido, fundamentales para la organización del discurso y para la construcción de los "mapas mentales" que estructuraban la percepción del mundo en la literatura griega y, posteriormente, del Imperium en los textos romanos. Un ejemplo sería el mapa de Agripa, mencionado por Plinio (3.17; cf. Whittaker, 2002, 85ss.; Talbert, 2004; Campbell, 2012, 65), que a su vez es importante para el conocimiento de las representaciones de Hispania en el siglo I a.C., en particular de las fronteras entre las provincias y de la percepción de elementos que definen los viajes como una secuencia de accidentes geográficos.

En estas descripciones, el Anas, actual Guadiana, se destaca como uno de esos elementos que estructuran estos "mapas mentales" y permiten al receptor tener una idea, aunque siempre muy parcial, de los territorios representados, casi siempre costeros. Resulta interesante constatar que hay un desequilibrio especialmente evidente entre los textos que presentan el Anas como frontera entre la Bética y la Lusitania (Plin., Nat., 3,6; Mela 2,6,8; Fig.1a) y la realidad arqueológica y epigráfica de los asentamientos que se distribuyen a lo largo de sus orillas, o incluso de sus territorios administrativos. En ese sentido, la bibliografía especializada hace hincapié en los problemas de interpretación de las fuentes y de la epigrafía sobre el Guadiana (García Iglesias, 1972; Francisco Martín, 1978; Sillières, 1982; Guerra, 1995, 47; Marcos, 2011) y la ubicación de las mansiones de los itinerarios (Roldán, 1975; Pastor Muñoz, 2004; Carneiro, 2010), algunas de ellas problemáticas.

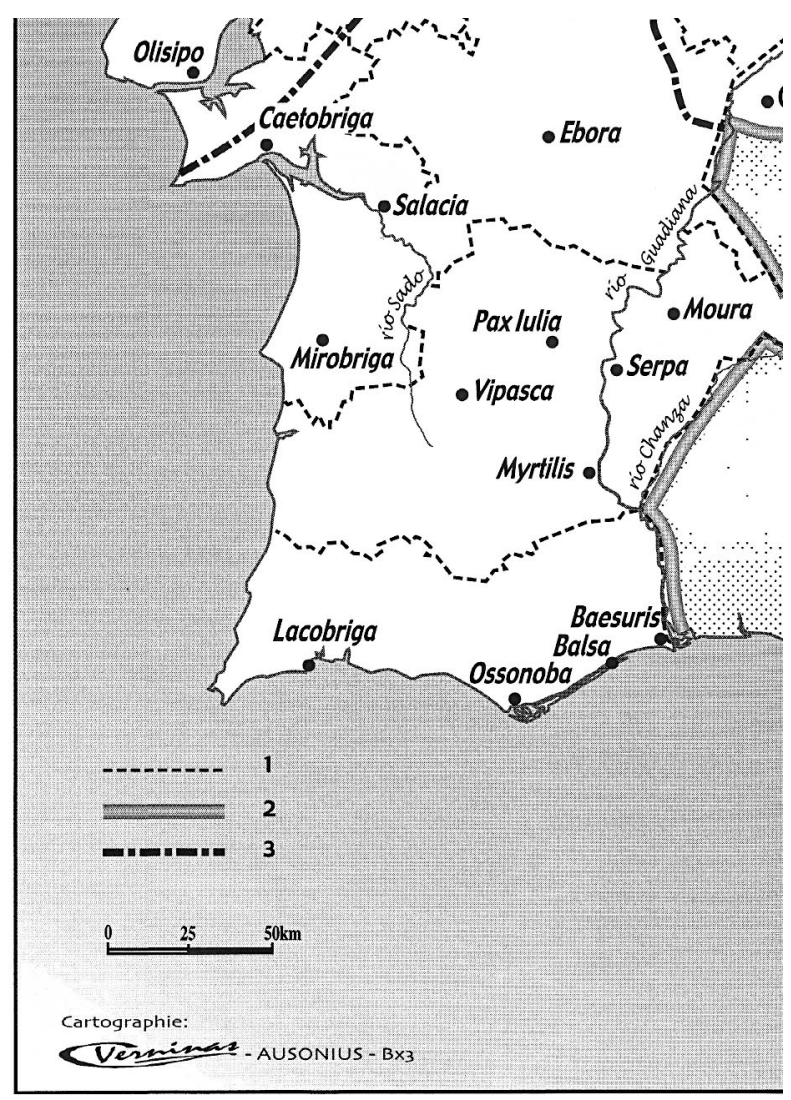

Fig. 1. Límites de la Lusitania romana, según Navarro y Ramírez coords., 2003. 
Parece así evidente que no se ha prestado suficiente atención a la posible tendencia de simplificación de la realidad peninsular en textos como, p.ej., el de Plinio y de Mela, en los que posiblemente no haría falta preseel ntar unos límites que serían incomprensibles para otros que no conocían los pueblos mencionados. Otro tanto puede decirse de la cronología y transmisión de las informaciones de los itinerarios, y de su aplicabilidad al tema de estudio que se propone en este texto (cf. Roldán, 1975).

Cabe, por tanto, plantear algunas cuestiones sobre el uso de los ríos como fronteras o elementos de delimitación. Valga como ejemplo el episodio de Julio César cuando cruzó el Rubicón en 49 a.C.: el río marca la frontera entre la Galia Cisalpina e Italia (Cic., Phil., 6,5) y el simple hecho de cruzarlo es un hito, desde el punto de vista de la memoria histórica, del inicio de una guerra civil (Suet., Jul., 31). El río estructura un relato y, al mismo tiempo, es una frontera que puede ser traspuesta con relativa facilidad. Asimismo, en Res Gestae (cap. 26) se constata que estos elementos geográficos delimitan la extensión del poder de Augusto. El Ebro, por su parte, era una frontera diplomática, virtual y temporal que pretendía establecer un límite entre dos hegemonías en 226 a.C., particularmente efectivo en un territorio que en este momento era poco conocido por Roma (Liv., 21,2,7; Curchin, 1997: 67; Cadiou y Moret, 2012, 22-23).

Desde un punto de vista militar, un río puede ser una barrera, sobre todo si en sus orillas se instalan estructuras defensivas (cf. Rankov, 2005, con discusión y bibliografía anterior). Por poner un ejemplo, en Caes., B.G. 5, 18, se señala la dificultad para cruzar el Támesis en los puntos que podía vadearse, y el uso de "estacas puntiagudas" en otros puntos, puestas por los enemigos. Todo depende de las condiciones naturales de cada región y de la necesidad de defender, o no, un territorio. Por otro lado, es evidente que los ríos son elementos geográficos que organizan un discurso como, p.ej., las descripciones de Estrabón sobre la historia y la mitología de un pueblo, llegando incluso a denominar provincias (p.ej. la Bética: Campbell 2012: 65) o regiones, si admitimos que el nombre Beturia, más territorial que étnica, es una fusión de Baetis y Urius (Corzo y San Gil, 1992, 165; cf. TIR J-29, s.u. Baetvria/ Baitovria).

Es preciso matizar algunas de estas informaciones textuales para desarrollar el estudio del Anas como frontera territorial. Sin embargo, las fuentes pueden transmitir algunos datos sobre los mecanismos de reconocimiento e imposición de límites en las más diversas circunstancias que sí importaría analizar, o la terminología griega y latina que se aplica a este tipo de situaciones. No obstante, la epigrafía y el registro arqueológico son las principales herramientas para una aproximación más completa al tema propuesto.

La documentación epigráfica del sur del territorio hoy portugués es una importante fuente de información para clarificar estas cuestiones, o por lo menos proponer nuevas interrogantes y perspectivas. El estudio de la epigrafía de Myrtilis (Mértola) es en ese sentido necesario por la importancia que esta ciudad tuvo como plataforma comercial y como punto privilegiado para la existencia de un posible escenario multicultural desarrollado con anterioridad (cf. Albuquerque y García, 2017a)1.

Desde el punto de vista arqueológico, el análisis del registro presenta dos vertientes: la primera tiene que ver con la comparación entre las realidades materiales de cada orilla y la caracterización de los asentamientos a lo largo del río, con el objetivo de analizar el poblamiento del Guadiana, en el que el río es el centro del discurso, un aspecto que aún no ha sido suficientemente valorado en la investigación (Albuquerque 2017). Ello es una consecuencia del uso actual del Guadiana como frontera entre países o entre municipios, lo que puede condicionar la investigación.

La otra vertiente analiza la construcción de fronteras simbólicas y sociales en estos territorios, p.ej. en lo que respecta a los contextos de consumo y a la diferenciación social (Albuquerque y García, 2017a; b). En este trabajo se presenta, aunque sin mucho detenimiento, la primera vertiente, circunscrita sobre todo al periodo que las fuentes escritas analizadas describen (es decir, anteriores a finales del siglo I d.C.).

1 Aunque no sea debatido en este trabajo, es igualmente relevante el estudio de epigrafía de los territorios atribuidos a los actuales municipios de Serpa y Moura, ambos en la orilla izquierda del río y con un conjunto interesante de documentos que complementan la información de Mértola, presentando además similitudes con el repertorio epigráfico de esta localidad alentejana en diversos aspectos, a saber, los rasgos constructivos de los monumentos y el elevado índice de romanidad de los individuos registrados. 


\section{LAS FUENTES CLÁSICAS}

El Guadiana es mencionado únicamente en fuentes posteriores al siglo III a.C., señalando una etapa de los viajes marítimos a lo largo de la costa o su cualidad de río navegable que establece los límites de un territorio o de un pueblo. Ello parece evidente en un texto de Marciano de Heraclea (siglo IV), cuando el autor afirma, en su Periplo del Mar Exterior (2,8), que

"La longitud de toda la Betica empieza desde la desembocadura del río Anas y termina en el nacimiento del mismo río [...]. En el sentido de la latitud comienza en las fuentes del mismo río y termina por el Sur en el templo de Juno."

(Trad. M. Pastor Muñoz, 1978)

Conocemos referencias a este río en las obras de Polibio, César, Estrabón, Plinio, Mela, en los itinerarios, en periplos como el de Marciano y en los textos de los agrimensores romanos. La información proporcionada por estos documentos, claramente insuficiente, puede ser complementada con un cuestionario sobre el uso de los ríos como referentes geográficos, como fronteras y como puntos estratégicos de defensa. Esto permite tener una idea general sobre la importancia económica y militar de los ríos y sobre el modo como el ejemplo del Anas se enmarca en otros del Imperium.

Hemos preferido dedicar algunas breves palabras a la epigrafía, puesto que estos documentos proporcionan informaciones determinantes para el estudio de las sociedades que vivían cerca del Guadiana o en lugares fronterizos (adscripción a tribus, orígenes, estatus social, etc.) e, incluso, de los límites de las ciudades (Roldán, 1975, 12-13; González, 2004).

Ello ha permitido desafiar la idea, transmitida en los textos de Mela y Plinio, de que el río separaba los territorios de Bética y Lusitania (Alarcão et al., 1990). Véase asimismo la opinión de A. Canto, en ERBC, 28, n. 39; 147, que parece admitir sin más la información de estos autores clásicos. Por otro lado, se destaca la representación del río como elemento geográfico que delimita los pueblos conocidos por Roma. Por ello, no es pertinente defender que tales fronteras se mantuvieron inalteradas a lo largo de los años (Canto, 1989, 151).

La importancia de los accidentes geográficos es evidente cuando se pretende presentar a los receptores una idea general de territorios no pocas veces desconocidos. Estrabón, p.ej., no tenía un conocimiento directo de la Península Ibérica, pero consultó a autores que sí habían estado y estudiado algunos aspectos de la naturaleza o de la etnografía de una Iberia que conocieron e en su tiempo.

La posible referencia más antigua a la Lusitania la encontramos en la obra de Polibio $(10,7,4-5)$, escrita a mediados del siglo II a.C., presentándose como la región más occidental del mundo habitado. Este autor habrá conocido la Península Ibérica en c. 151 a.C. (cf. Pérez Vilatela, 2000, 23ss.), acompañando los primeros pasos de Roma en el conocimiento geográfico de este territorio tras la segunda Guerra Púnica (cf. Plb., 3,37.10-11; 3.39.4-5, apud García Fernández, 2003, 59). El megapolitano menciona una vez el río para decir que nacía en Celtiberia $(34,12$ = Str, 3,2,11; cf. Cruz, 2006, 8586 ), por lo cual no tendrá aquí un comentario más desarrollado.

Recientemente, la publicación del Papiro de Artemidoro (Pap. Art.) ha dado pie a una importante discusión sobre su autenticidad y sobre algunos topónimos de Lusitania, como Salacia/ Salakeia (Faria, 2009). Esta obra, fechada entre 104 y 101 a.C., es presentada como un periplo que describe la costa y las distancias entre lugares y fue una de las principales fuentes de Estrabón, directa o indirectamente (por intermedio de Posidonio: Schiano, apud Ruiz y Campos, 2009, 91, n. 7; Cruz et al., 2009, 318-319). De las cinco columnas del papiro, dos se refieren a la Península Ibérica, destacándose, para los propósitos de este trabajo, una posible mención al Anas y a una ciudad supuestamente ubicada en su estuario, Cilibe. Sobresalen de antemano dos problemas: el hidrónimo es una interpretación de dos lagunas en el papiro ${ }^{2}$ y de Cilibe solo conocemos un etnónimo (Cilibitanos) de una lista de ciudades estipendarias de Lusitania (Plin., Nat., 4,118). El nombre tiene lecturas diferentes según los códices, entre Cilibitani y Cibilitani, predominando la última. Ello permitiría defender, según J.M. Ruiz y J.M. Campos, que esta ciudad se ubicaba en el Cerro de Rocha Branca (Silves) y que el A[rados] (actual Arade) sería el río mencionado en el Pap. Art., quedando así explicada la referencia a dos ciudades, Ipsa y Cilibe/Cibile (sic), con argumentos basados en los hallazgos numismáticos que ubican estas ciudades, respectivamente, cerca de Portimão

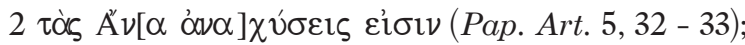
$\tau \hat{\omega}\left[v A^{\prime \prime}\right] v \alpha \dot{\varepsilon}[\kappa \beta о \lambda \hat{\omega}] v$ (ibid.: 34). 
y Silves (cf. Guerra, 2007, 121-123; Ruiz y Campos, 2009, 102, fig. 3; Alarcão, 2010, 108).

Este tema merece una discusión más profunda, sobre todo porque puede ser relacionado con las referencias a Baesuris (actual Castro Marim) o, mejor dicho, con la ausencia de testimonios textuales de su existencia anteriores a los itinerarios, a pesar de la importancia económica que este asentamiento tuvo antes del siglo I d.C.; resulta evidente que Artemidoro pudo haber conocido Baesuris, directa o indirectamente, puesto que en ese momento estaba activa.

Otras fuentes señalan que el Anas era un referente geográfico. La obra de Julio César, De Belo Civile, menciona el río como elemento que delimita la acción militar, pero no profundiza en otros aspectos como, p.ej., su importancia para la defensa de los ejércitos (Caes., BC, 38), al contrario de otra ocasión, en la cual el autor anónimo de Bellum Hispanicum destaca esa potencialidad en el Baetis $(B H, 5) y$, un poco más adelante, menciona la importancia de las torres y de las murallas construidas en lugares deshabitados (id. 8,3, apud Cadiou y Moret, 2012, 39-40).

Las obras más detalladas son las de Estrabón, Mela y Plinio. El primero consultó algunas fuentes (p.ej., Polibio, Artemidoro, Eratóstenes, Posidonio) para crear una imagen de la Península Ibérica en su Geografía, destacando, sobre todo - en el caso del Anas - la navegabilidad y los límites de algunos pueblos que cita a lo largo de su libro 3. El testimonio estraboniano es importante para conocer los intereses de la representación etnográfica del Imperium, en particular de Iberia en c. 17 - 18 d.C.; del mismo modo que los textos que señalaremos a continuación, el del amasiano no presenta datos suficientes sobre los pueblos que vivían en las orillas del Guadiana, puesto que tampoco les da demasiada importancia.

Entre 43 y 44, Pomponio Mela, nacido en Tingentera, escribió una Corografía en la cual pretendía transmitir a sus receptores algunas informaciones muy generales sobre el mundo habitado. Los primeros párrafos $(1,1-2)$ dan cuenta de los objetivos del autor y de una obra que pensaba publicar $a$ posteriori con informaciones más completas, pero de esta nada se conoce. En ella quizás hubiese desarrollado más sus informaciones sobre Hispania.

Los libros 3 a 6 de la Historia Natural de Plinio el Viejo, por su parte, ofrecen una perspectiva detallada de la organización del territorio del Impe- rio en general y de la Península Ibérica en particular (libros 3 y 4), señalando los estatutos de algunas ciudades ante el poder de Roma (Talbert, 2004, 24). Los datos que presenta no están exentos de problemas y de discusión, dependiendo de las fuentes del autor o de su conocimiento sobre la realidad peninsular que describe. Ello es evidente en el contraste entre el rigor de las informaciones sobre la Tarraconense (de la cual disponía de datos actualizados) y las otras dos provincias, la Bética y la Lusitania (Guerra, 1995, 19-20; Faria, 1995; 2001). Es decir: algunas informaciones podrían estar ya desactuali-

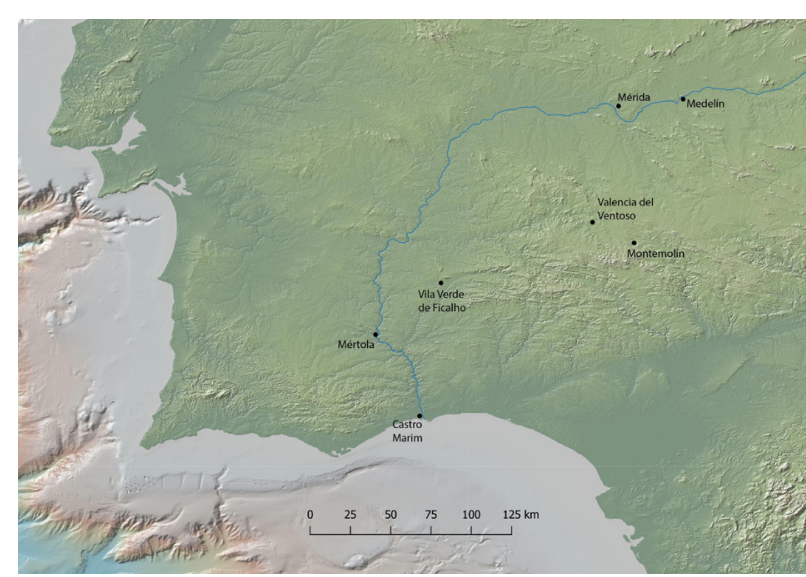

Fig. 2. Área tratada en este trabajo, con indicación del Guadiana y ubicación de algunos yacimientos mencionados. Mapa base: Global Multi-Resolution Topography (elaborado por Carlos Pereira).

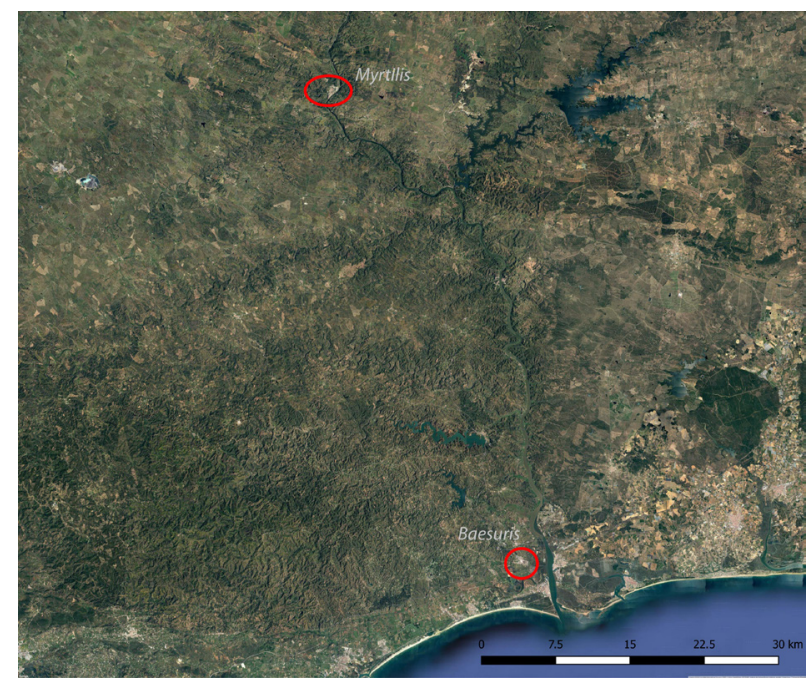

Fig. 3. El Guadiana entre Baesuris y Myrtilis. Mapa base: Open Layer Plugin (elaborado por Carlos Pereira). 
zadas en el momento en que Plinio escribió, sobre todo en lo que respecta a la Lusitania.

Los itinerarios son igualmente problemáticos, pero indican la existencia de sistemas de comunicación que pasaban por diversos puntos (o mansiones) cuya identificación no siempre es consensual, como parece ser el caso de Fines (cf. ERBC, 147; TIR J-29, s.v. Fines; Ramírez Sádaba, 1994, 347; Navarro y Ramírez, 2003, 44). En algunos casos son los únicos textos que transmiten un nombre (p.ej., Baesuris, identificado sin gran discusión con Castro Marim: Arruda, 1999/2000, 36; TIR J-29, s.u. Baesuris). Esto no significa que la información sea suficiente o que tenga un elevado grado de credibilidad. Por ejemplo, uno de los itinerarios entre Baesuris y Pax Ivlia (It. Ant. 425.6 - 427. 3) es uno de los pasajes más problemáticos de toda la obra, en lo que respecta a la secuencia de mansiones (Roldán 1975, 77-78; Carneiro, 2010, 83-85).

Por su parte, los textos de los agrimensores transmiten lo que sería la metodología de elaboración de un mapa (forma) de las centuriaciones, lo que parece encontrar correspondencia con una inscripción (Sáez, 1990; Ariño y Gurt, 1994, 60-64), en la cual se menciona explícitamente el territorio de Lacimurga y el Anas. Este tema fue discutido por L. García Iglesias (1970) en el ámbito de sus estudios sobre los límites de la Bética y de la Lusitania (asimismo, Sáez, 1990, 218; Mayer 2004, con una reflexión sobre los textos de los agrimensores, que definieron los métodos de la organización de las centuriaciones en comparación con la epigrafía.

Todo ello lleva a considerar la cronología de los textos y de las informaciones que transmiten, lo cual es especialmente relevante en el caso de los itinerarios (Roldán, 1975, 20-21) y de las fuentes consultadas por otros autores clásicos en el siglo I d.C., que representan algunas etapas de la administración romana con respecto al Guadiana como frontera entre regiones y pueblos (p.ej., Str, 3, 1.6; cf. Faria, 2001). Sin embargo, en estas fuentes se destaca la importancia de los ríos como elementos que estructuran las representaciones de otros pueblos, como puntos de referencia para definir límites y/o espacios de transición (una importante discusión en Rankov, 2005, con bibliografía, y Campbell, 2012).

\section{2. ¿EL GUADIANA COMO FRONTERA?}

"[...] Los límites de la provincia fueron los mismos de las espadas y de los dardos"

$$
\text { Cic., Pis., } 38^{3}
$$

La terminología latina utilizada para contextos fronterizos (limes, finis, terminus, etc.) no se identifica en los pasajes de los autores clásicos que mencionan el Guadiana, sino la idea de que el río era un referente geográfico que separaba dos provincias (Plin, Nat. 3.6: "amne Ana discreta"; Mela, 2,6,87: "illas fluvius Anas separat"). Esta condición de marcador fronterizo podría implicar el uso de un término como ripa ("orilla", "margen"), aceptando la interpretación propuesta por G. Isaac (1998, 350). Sin embargo, ripa es un elemento de descripción que, aislado, no tiene el significado de frontera, siquiera natural (cf. Mela 1,10 y 15). Por su parte, Estrabón afirma que el río delimita los territorios de célticos, lusitanos $(3,1,6)$ y de Turdetania (3.2.1), revelando una organización del discurso en torno a estos elementos naturales, quizás con el mismo objetivo de transmitir al receptor una idea general del territorio y de los pueblos que describe, sin que para ello sea necesario reflexionar sobre los muchos matices de estas informaciones (vid. supra).

Topónimos como (Mansio ad) Fines pueden igualmente indicar la existencia de lugares fronterizos en la Tarraconense (Ant., 398,5; Rav., 303,10), Bética o Lusitania (Ant., 427,1; Rav. 317.18). En ese sentido, valga como ejemplo Suet., Jul., 31, sobre el Rubicón: "Cuando hubo alcanzado a sus cohortes junto al río Rubicón, que señalaba el límite de su provincia"4. La identificación de Fines en Vila Verde de Ficalho (Fig. 1; TIR J-29, 69 y 79-80) permite afirmar que en este caso sería el Chanza que definía la frontera. Sin embargo, A. Canto lee el topónimo como "territorio" (ERBC 1994, 147, n. 86) y J.M. Ramírez (1994, 347) como "límite" (cf. Navarro y Ramírez, 2003, 44). En ese sentido, el hallazgo del miliario de Corte do Alho, fechado en c. 121 d.C., por F. de Lima en 1951 (entre otros, ERBC, 147; TIR, J-29, s.u. Corte do Alho; HEp, 1994, 1001) ha sido determinante para ubicar Fines en Ficalho.

3 Trad. Sílvia Teixeira: “[...] fines provinciae fuerint qui gladiorum atque pilorum"

4 Trad. R.M. Agudo Cubas (Picón y Agudo, 2008): "Consecutusque cohortis ad Rubiconem flumen, qui provinciae eius finis erat”. 
Dejaremos para otra ocasión la discusión sobre este tema. No obstante, cabe referir la importancia económica de los ríos navegables y de sus afluentes (Str., 3,3,1; 3,2,5; Lopes, 2006; Parodí, 2014). Esta potencialidad se traduce en el flujo de gentes, productos e ideas en los territorios que mantenían contacto con el río y se repercuten, además, en el contexto del Guadiana. El río separaba, en algunos tramos (quizás entre la desembocadura y Mértola), dos provincias (cf. Infra), pero la mayor parte de los productos consumidos en el sur de la Lusitania procedían de la Bética (Viegas, 2011, 516ss; Pereira, 2014, 447-448), merced del transporte y explotación de los recursos marinos, lo que se refleja en la primacía de los contactos con la Bética en detrimento de la capital provincial, Emerita. Hay, en este sentido, una continuidad que no traduce dicha idea de separación y que permite defender en términos muy genéricos la poca importancia de la frontera territorial en lo que respecta a la adquisición y circulación de bienes.

Por poner un ejemplo, se constatan grandes similitudes entre el registro funerario de Ossonoba (Faro) y el de Onoba (Huelva), ciudades respectivamente de la Lusitania y de la Bética, a pesar de algunos regionalismos. Esta situación se constata en el restante territorio meridional (Bernardes et al., 2014) y lleva a concluir que el Anas no impuso ningún tipo de aislamiento en época romana (cultural o económico) entre áreas vecinas de larga tradición comercial (Arruda, 2003). De hecho, en el mundo de la muerte es más visible una dicotomía entre litoral/interior que entre Lusitania/ Bética. Dicha realidad no se manifiesta únicamente en los materiales aplicados en las construcciones funerarias, en la arquitectura o en los productos que acompañaban al difunto: también es visible en los ritos practicados. Los enterramientos infantiles en ánfora, p.ej., es una realidad plenamente constatada en el litoral que no tiene paralelo en el interior (Pereira y Albuquerque, 2018).

La epigrafía no contradice este panorama, puesto que se comparten algunos gentilicios entre las elites de la Lusitania y de la Bética. Ello indica la existencia de relaciones de parentesco y/o dependencia entre ellas. Ello puede tener que ver con el ejercicio de la explotación de mármoles en el sur de Lusitania, lo que puede relacionarse con el hecho de que algunos monumentos epigráficos de esta provincia o las obras públicas estaban construidos con este material en la Bética (Dias y Coelho, 1995-97, 250-252).
Los asentamientos litorales, obviamente, son en parte responsables de estas relaciones comerciales, de la llegada de algunos elementos al interior y, por consiguiente, de la integración de estas poblaciones en circuitos comerciales más amplios (Fabião, 2009, 58). Sin embargo, muchas modas no llegaron al interior con la misma fluidez que se manifiesta en los asentamientos del litoral (Chic, 2005, 322323), como acabamos de constatar en el ejemplo de los enterramientos infantiles en ánforas y al cual podríamos añadir otros. No obstante, los asentamientos que controlaban las desembocaduras de los ríos, como Castro Marim en el Anas, garantizarían la protección de la circulación hacia los territorios interiores y su fluidez (entre otros, Arruda, 1988; 2003), en particular hacia Mértola, en el límite de la navegabilidad del río (Albuquerque y García, 2017a; García, Albuquerque y Palma, 2017).

A esta función de "carretera" se añade la de defensa, que complementa la protección de poblados. Esta dualidad depende de las particularidades del territorio y de las circunstancias históricas que conducen a que se valore una u otra función. Lo dicho es especialmente válido para la época romana-republicana: los ríos eran vías de abastecimiento de los ejércitos, de salida de materias-primas del interior (Morillo y Salido, 2010, 149-151) y, simultáneamente, importantes barreras naturales en los puntos en que estaban encajados en el paisaje. En resumen, los ríos son determinantes en el dominio y control del territorio en los más variados ámbitos (explotación, comercialización, pacificación, vigilancia). Ello justifica la necesidad de garantizar su control (César, $B G 5.18 ; B H$, 5; cf. Rankov, 2005) y puede explicar el hecho de que los militares debiesen practicar la natación en los meses de verano, puesto que les permitiría atravesar los grandes ríos cuando el ejército estaba en marcha o salvarse cuando la lluvia hacía subir el nivel del agua (Vegetius, Epitoma Rei Militaris, 1.10).

En los apartados siguientes señalaremos algunas cuestiones que nos parecen pertinentes para discutir el papel del Anas como elemento fronterizo, en lo que respecta a la separación entre la Bética y la Lusitania (Figs. 1 y 2) y a la navegabilidad del río. Éste puede ser un elemento visible que permite la identificación de los límites de un territorio, pero eso no implica que se simplifique la realidad hasta tal punto que se considera que la margen derecha del río pertenece a la Lusitania y la izquierda a la Bética, como aparentemente señalaron en su tiempo Mela y Plinio. 
Antes de estos autores, la descripción de las incursiones de pueblos indígenas en territorios dominados por Roma, entre 194 y 151 a.C., permite suponer que no existían fronteras strictu sensu, puesto que no hay referencia a una situación de violación de un espacio delimitado, sino ataques a poblaciones que eran protegidas por la potencia dominante (cf. Livio y Apiano, apud Cadiou y Moret, 2012, 31, n. 40). Se trata por tanto de zonas de frontera, no líneas de frontera, sobre todo en el periodo romano-republicano (Curchin, 1997, 67). Esta indefinición es un punto de partida para cuestionar el momento a partir del cual el Anas es, o no, un elemento que separa o une las ciudades o los pueblos que forman parte de un sistema de poblamiento reconfigurado por el poder romano. En otras palabras, las fronteras son definidas por los grupos poblacionales y su importancia depende de las circunstancias históricas. Quizás por ello, el río no es mencionado en las fuentes con ese sentido o como elemento que responde a una necesidad de defensa.

\section{El $A N A S$ y LAS PROVINCIAS ROMANAS}

Todo ello induce a pensar que las fronteras interprovinciales correspondían a los límites de los territorios de las ciudades y pueblos que quedaban dentro del dominio de una provincia y, por ende, de Roma. No hay, por consiguiente, que buscar explicaciones en una perspectiva geográfica que, por lo que podemos observar en todo este panorama, solo es valorada en textos que intentan describir la extensión del poder de Roma (cf. Cadiou y Moret, 2012, 28-29). Asimismo, para Curchin, "the rivers were thus not a line to advance to, but a line to advance along. Accordingly, the frontier did not run along populated river valleys but across the sparsely inhabited wastelands between them" $(1997,67)$.

Hemos visto que las referencias de Mela y Plinio al Anas como elemento geográfico que separaba la Bética y la Lusitania pueden ser matizadas, y a ello se añade la discusión sobre los límites del territorio de ciudades como, p.ej., Mérida (entre otros, Ramírez Sadaba, 1993; cf. Favory, 2005; Gargola, 2005). Un texto, tardío, del agrimensor Agenio Úbico (Thulin, 1913, 44), atribuido a Frontino por Lachmann (propuesta aceptada, entre otros, por Sillières, 1982, 438; Alarcão et al., 1990, 322, n. 14), señala que el Anas estaba en medio de la pertica (o forma) de la capital de la Lusitania y que se distribuyeron tierras en sus orillas; es evidente que el río no es en este caso una frontera, sino los espacios ocupados por los colonos:

"Sé que, en Lusitania, en el territorio de los emeritenses, una parte considerable del río Ana atraviesa la pértica de la colonia, en cuyos márgenes se asignaron campos hasta donde entonces pareció útil. Dadas las grandes dimensiones del terreno, estableció veteranos en torno casi a la linde extrema, así como los confines, muy pocos junto a la colonia, y junto al río Ana; el resto había quedado para cubrirlo después”.

(Agen., Agrim. 228-229, trad. P. Resina, THA III: 271-272) ${ }^{5}$

Esto también se desprende de una inscripción catastral publicada por P. Sáez (1990). En ella, se representa una centuración, asociada a Lacimurga, que es atravesada por el río. (v. Fig. 1). Dos termini augustales de Valencia del Ventoso y Montemolín (Ramírez, 1993) indican la existencia de enclaves emeritenses fuera, incluso, del territorio atribuido a Lusitania y lejos del Anas (Fig. 1). Resulta por lo tanto evidente que las fuentes no señalan con rigor cuestiones que tienen que ver con la organización territorial de cada ciudad.

A pesar de los problemas de los planteamientos iniciales de Hübner sobre la cuestión de Metellinum (CIL II, 72 y mapa; Guerra, 1995, 48-49; Plin., Nat, 3,6; 4,116; Ptol., 2,5,6), se propusieron diversas interpretaciones de los documentos epigráficos (García Iglesias, 1972; Francisco, 1978; Guerra, 1995, 49, etc.), e incluso un cambio en el curso del río durante la Antigüedad para justificar este apriorismo (Monsalud, 1897, 488; García Iglesias, 1972, 166). Todo ello revela una primacía de aquellos textos en el análisis de las fronteras territoriales en la investigación, pero esta dependencia se hace cada vez menos visible.

Este panorama ha conducido a replantear la

5 "Scio in Lusitania, finibus Emeritensium, non exiguum per media coloniae perticam ire flumen Anam, circa quod agrisunt adsignati qua usquel tunc solum utile visium est. / Propter magnitutiduninem enim agrorum veteranos circa extremum fere finem velut terminos disposuit, paucissimos circa coloniam, et circa flumen $\mathrm{A}<\mathrm{nam}>$ : reliquum ita remanserat, ut postea repleretur" (Thulin, 1913: 44; cf. Higino, 1.28; Frontino 2.13, sobre las centuriaciones de Emerita y comentarios de Sáez, 1990; Ariño y Gurt, 1994, $45 s s)$. 
configuración de la Lusitania romana partiendo de la relación entre el curso fluvial y el registro arqueológico y epigráfico. Se concluyó, p.ej., que las fronteras naturales "servent surtout à asseoir les grandes limites administratives dans la mesure où elles forment des barrières géographiques stables et bien repérées, mais elles ne coïncident pas toujours avec la réalité des civitates ou des identités ethniques" (Alarcão et al., 1990, 327). En otras palabras, es imprescindible matizar la idea de que una frontera o, en este caso, un río, imponen alguna discontinuidad cultural. Se puede afirmar, aunque provisionalmente, que las orillas de un río pueden ser elementos estructurantes de poblamiento y formar un sistema de relaciones de pertenencia, independientemente de ser, o no, un elemento fronterizo.

\section{Entre BAEsuris y Myrtilis}

"El Anas resulta también remontable para la navegación, pero no para tales navíos ni durante tan gran trecho."

Str., $3,2,3$

El análisis de estos sistemas estructurados por los ríos, en particular del Guadiana, cobra especial interés si tenemos en cuenta las ventajas de la navegabilidad hasta Mértola (Fig. 3). Admitiendo que la frontera entre provincias se ha definido entre la desembocadura de este río y la desembocadura del Chanza (Fig. 1), donde se encuentra actualmente Pomarão, es importante cuestionar hasta qué punto esta condición tuvo, o no, consecuencias en el tráfico fluvial entre Baesuris y Myrtilis y en las estrategias de control de los recursos.

Parece obvia la importancia de los asentamientos portuarios si nos fijamos, p.ej., en la creación de capitales de civitates en ciudades como Olisipo, Salacia, Balsa, Ossonoba y, por supuesto, Myrtilis (Blot, 2004, 472). Por esta razón, nos detendremos en una breve reflexión sobre la importancia de yacimientos como Castro Marim y Mértola.

La valoración de Myrtilis es determinante para el estudio de las fronteras: en primer lugar, por su ubicación estratégica en la circulación fluvial y terrestre; en segundo, por su capacidad defensiva en la margen derecha del Guadiana; en tercero y último lugar, por su posible función como puesto fronterizo en varias épocas. Estos elementos justifican claramente la importancia de esta ciudad y de su entorno para el estudio de las fronteras territoriales/ físicas y sociales/ simbólicas (cf. Albuquerque, 2017; Albuquerque y García, 2017a; 2017b; García, Albuquerque y Palma, 2017).

La información de Estrabón sobre las dos bocas del Guadiana permite tener una idea de cómo sería el paisaje alrededor de Baesuris a finales del siglo I a.C. y de su importancia para la circulación fluvial. Ello conduce a cuestionar las pocas referencias a este yacimiento en las fuentes y el porqué de solo ser conocido en los itinerarios, señalándose las comunicaciones viarias con el interior (It. Ant., 425,4; 431,4-8: Esuris; Rav., 305,9: Baesuris; cf. Arruda, 1999/2000, 36, con bibliografía).

Esta condición puede justificar una menor importancia en el contexto de la circulación a lo largo de la costa. Las descripciones antiguas son esencialmente costeras, y en ese sentido el río es mencionado como elemento que delimita la representación de la costa meridional de Lusitania hasta el Promotorio Sagrado. Baesuris había perdido, ya en el siglo I d.C., la importancia que antes tenía. Estos argumentos pueden ser suficientes para justificar la ausencia de referencias en dichos textos y, sin embargo, no son suficientemente fiables para describir el panorama arqueológico que en los últimos años se dio a conocer a la comunidad científica en diversas publicaciones de investigadores de la Universidad de Lisboa ${ }^{6}$.

La ubicación de Castro Marim (Fig. 4) parece ser determinante en la circulación fluvial del Guadiana y puede ser analizada como parte integrante de un sistema de poblamiento y explotación del territorio del cual Myrtilis (infra) y los Castella formaban parte, a saber, como un punto de contacto entre el litoral y el interior. Baesuris presenta genéricamente la misma cronología de los recintos fortificados del interior y no presenta indicios de una funcionalidad militar. Sin embargo, sus características defensivas indican, del mismo modo que los castella, un escenario de desconfianza o, por lo menos, alguna necesidad de protección y vigilancia en la segunda mitad del siglo I a.C.

La pérdida de importancia de los castella del interior encuentra alguna correspondencia con la secuencia ocupacional de Baesuris, que a finales del

6 La bibliografía citada a continuación no es exhaustiva. Algunos materiales de la Edad del Hierro y del periodo romano de Castro Marim fueron estudiados en el ámbito de trabajos de fin de Máster, y estos pueden ser consultados en el repositorio de dicha universidad. 


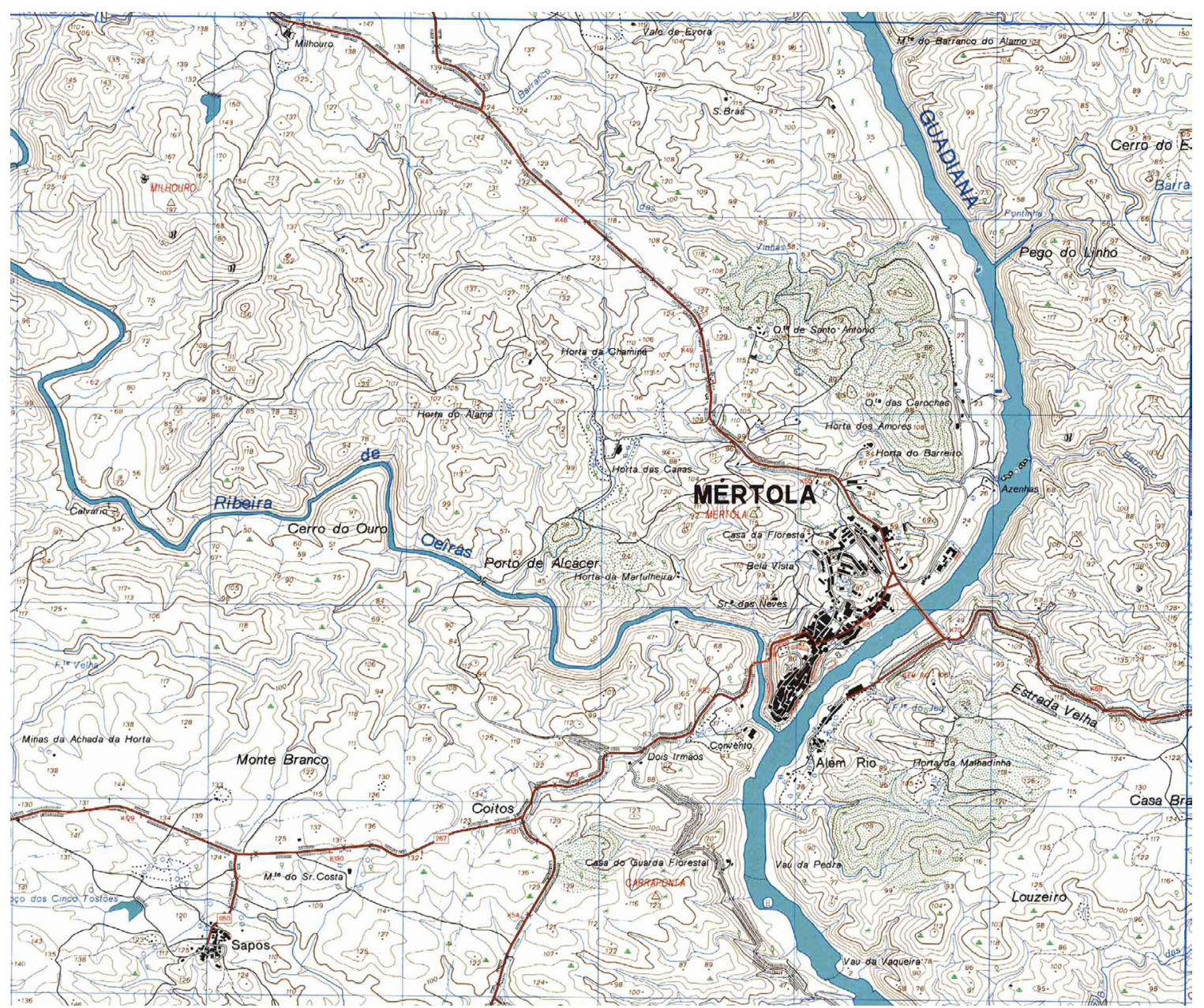

Fig. 4. Mértola: CMP 1/25000, hoja 558.

siglo I d.C. pierde la pujanza que tenía desde, por lo menos, el siglo VII a.C. (Arruda, 1988; 1999/2000, 33ss.; Viegas, 2011, 521). A su vez, la ocupación romana-republicana del vecino Forte de São Sebastião (Fig. 4) parece ser densa, pero solo entre finales del siglo II a.C. y las primeras décadas del siguiente, revelando una fase inicial de la conquista romana que no se traduce en una superposición a la ocupación prerromana del vecino castillo de Castro Marim. Éste, además, se "romaniza" definitivamente en la segunda mitad del siglo I a.C. (cf. Arruda y Pereira, 2008, con una descripción más detallada de los hallazgos). Se asiste, por tanto, a una aparente decadencia de estos yacimientos de la orilla derecha del Anas en el siglo I d.C., lo que contrasta, como veremos a continuación, con Mértola (Fig 4).

La antigua Myrtilis se fundó sobre un cerro ubicado junto a la desembocadura de la ribera de Oeiras en el Guadiana (Figs. 5 y 6), con buenas con- diciones de defensa, complementadas además con una potente muralla que sobrepasa el área actualmente ocupada por la villa, fechada entre los siglos VII y II a.C. (Hourcade et al., 2003). Su posición es estratégica desde el punto de vista económico: en el oppidum confluyen importantes vías terrestres que conectan Mértola a las regiones mineras (p.ej., São Domingos), a Pax Iulia y a poblados costeros como Baesuris (Lopes, 2006). Sin embargo, es la importancia de esta villa alentejana como puerto fluvial la que justifica una ferviente actividad comercial que se manifiesta en los datos recientemente exhumados de las excavaciones arqueológicas urbanas (entre otros, Palma, 2009; 2016; Lopes et al., 2010; Sorìa y Palma, 2017; Albuquerque y García, 2017a; García, Albuquerque y Palma, 2017), o incluso en las monedas (cf. infra) y otros que no pudieron ser estudiados con profundidad (por razones ajenas a los investigadores), a saber, estructuras 


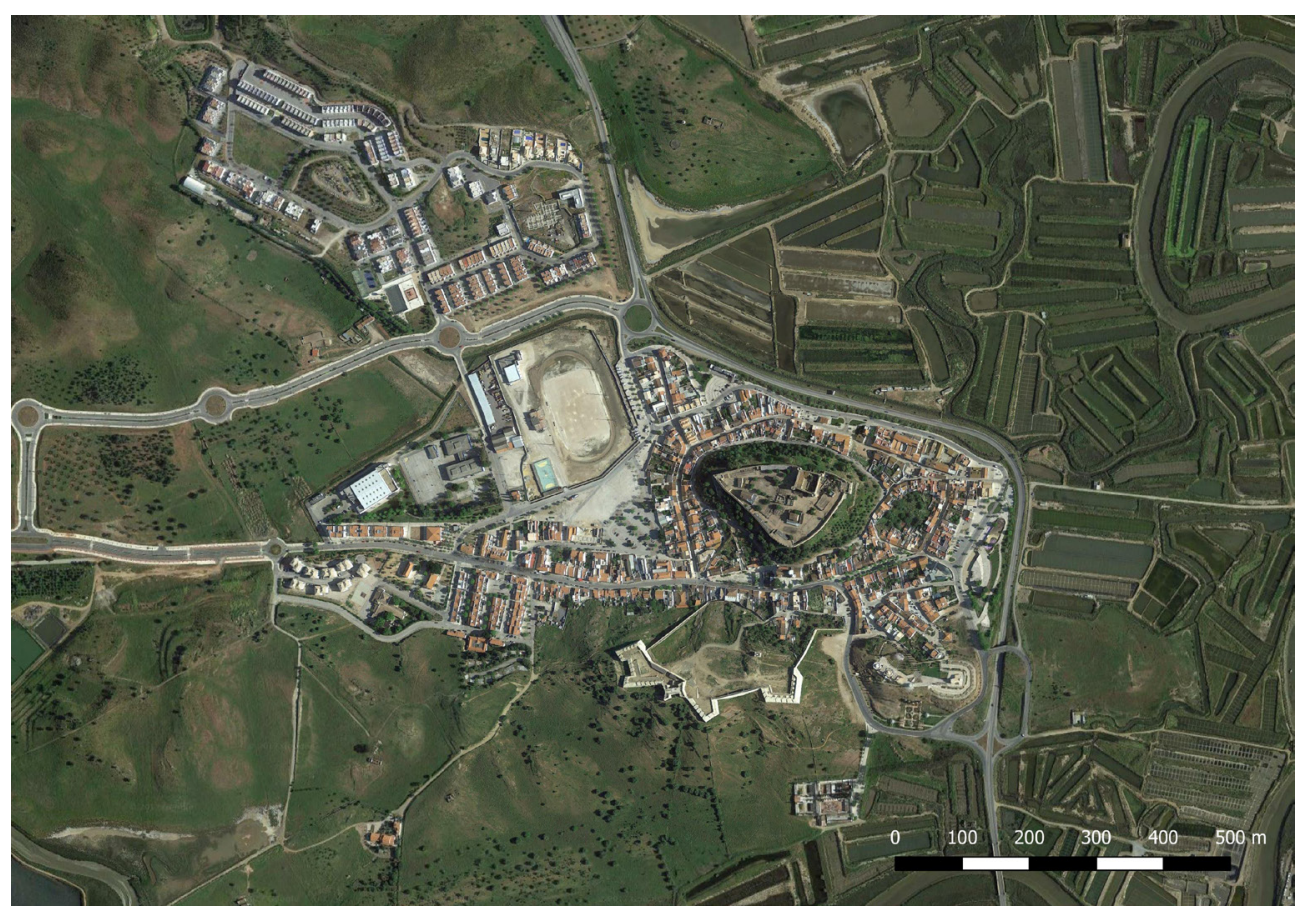

Fig. 5. Castro Marim (Castillo y Forte). Open Layer Plugin.

aparentemente portuarias de difícil interpretación identificadas en prospecciones subacuáticas (Simplício et al., 2003, 45-46).

El panorama de la Edad del Hierro y los primeros años de la presencia romana era apenas conocido, merced de publicaciones dispersas de materiales que, lamentablemente, procedían de contextos secundarios que no permitían una interpretación de conjunto rigurosa, a pesar de los encomiables esfuerzos de sistematización (Fabião, 1987; Rego et al., 1996; Arruda et al., 1998; Luís, 2003a; Barros, 2008; 2010; 2012). Recientemente, la publicación de la Carta Arqueológica do Concelho de Mértola (Palma, coord., 2012) supuso un hito de la investigación, puesto que ha logrado presentar un importante número de yacimientos resultantes de las prospecciones de los años 90 en el territorio de Mértola y las que han sido realizadas para la elaboración de esa obra (cf. Albuquerque y García, 2017a, 19ss.).

En lo que respecta a los primeros años de la ocupación romana, en Mértola se han identificado materiales que permiten pensar en su importancia como base de las operaciones militares romanas durante las guerras lusitanas (Fabião, 1987, 147; Luís, 2003a, 51ss., con bibliografía), lo que además parece manifestarse en el territorio circundante (Luís, 2003b). Las monedas identificadas, en particular su iconografía, han dado a su vez pie para definir con más precisión el carácter minero de la explotación de su entorno, o incluso el papel estratégico de Mértola en el contacto entre el interior y la costa, en particular durante el siglo II a.C., en el que se fechan estos numismas (Chaves y García, 1994, 391). No es preciso profundizar esta discusión en el presente artículo (cf. Albuquerque y García, 2017a, 12-14), pero habría en ese caso que destacar la asociación de las monedas mirtilenses a grupos itálicos que se instalan en esta región en estos momentos.

Aunque no sea ésta la ocasión para discutir con más detalle la secuencia ocupacional de Myrtilis y su territorio (lo que se ha hecho en otros trabajos: Palma, 2009; 2016; Palma, coord., 2012; Albuquerque y García, 2017a; García, Albuquerque y Palma, 2017), sí es relevante destacar que a los elementos brevemente expuestos en las líneas precedentes se suma un importante conjunto epigráfico. La epigrafía de Mértola presenta cronologías que exceden los límites cronológicos impuestos para este trabajo (la mayoría es del siglo II d.C. o posterior), pero los datos que proporcionan permiten constatar lo que se sospecha de la interpretación de los materiales arqueológicos hasta ahora conocidos, a saber, la presencia de una población de orígenes muy diversos. 


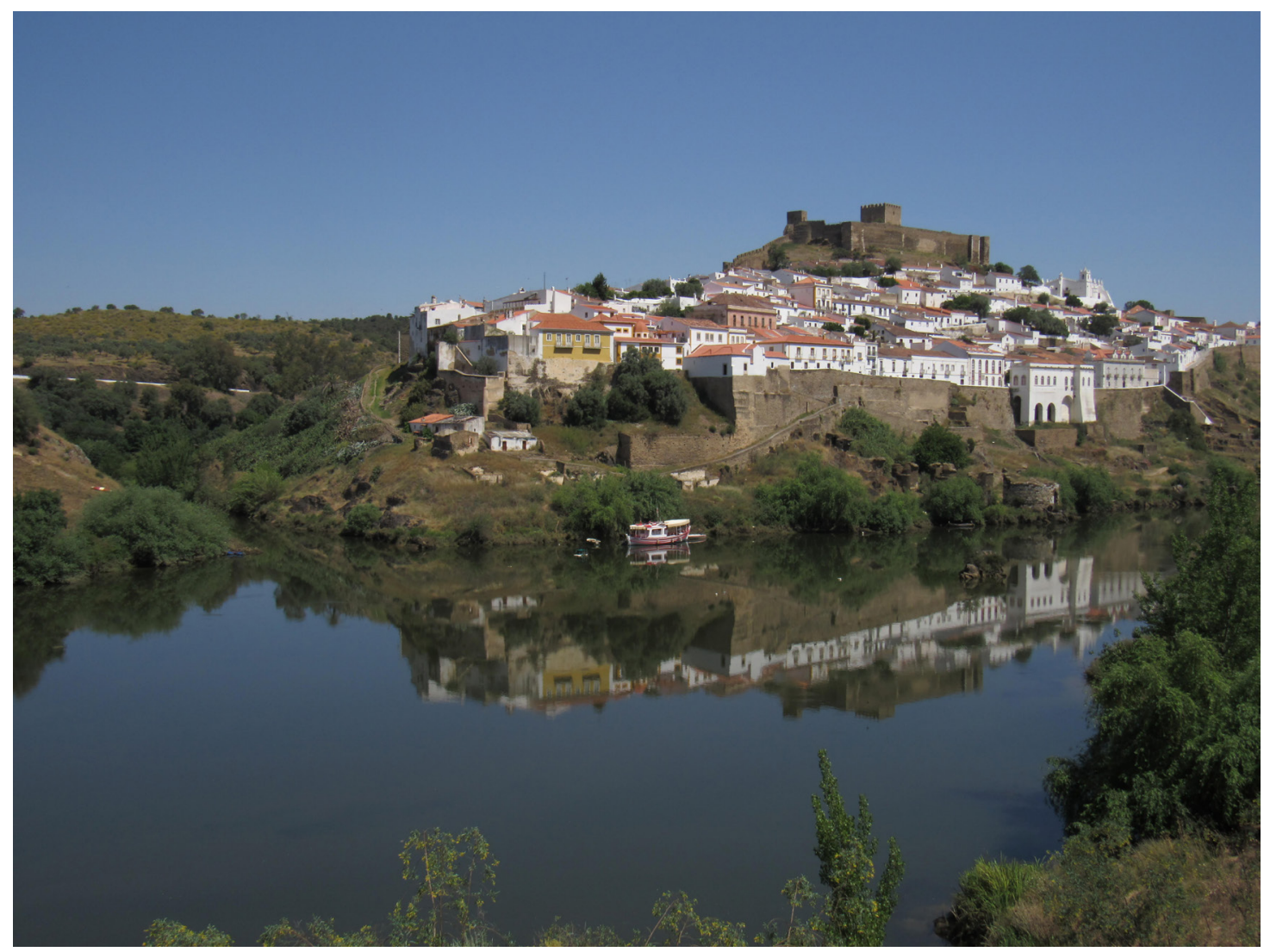

Fig. 6. Mértola: vista além-rio (foto de Pedro Albuquerque).

Desde el punto de vista de la onomástica, cabe destacar la identificación de un individuo itálico (IRCP, 98) y otro del África proconsular (IRCP 99; también mencionado en un epígrafe de Serpa: HEp 7, 1154). Por su parte, gentilicios como Helvius (1), Herennius (2), Memmius (1) y Valerius (1) se documentan en las familias senatoriales de la Bética (cf. IRCP, 100ss.). El corpus epigráfico conocido indica una escasa presencia del elemento indígena. Sin embargo, destaca la identificación de dos inscripciones de personajes con elevado estatus y poder adquisitivo (IRCP, 97, 103). Estos elementos, a los cuales se podrían añadir otros que serán tratados en otra ocasión con más detenimiento, son argumentos suficientes para demostrar el papel de Mértola en el contexto del comercio mediterráneo.

En 2016 y 2017, las campañas de prospecciones arqueológicas en las dos orillas del Guadiana tuvieron como principales objetivos caracterizar la proyección de esta importancia comercial de Mértola en el territorio y en el poblamiento a lo largo del río, considerando que se trata de un eje centralizador de la ocupación humana. Hasta este momento se publicaron algunos resultados de la primera campaña realizada en el norte del municipio (García, Albuquerque y Palma, 2017).

Los datos obtenidos, principalmente en las excavaciones arqueológicas de la Biblioteca (Palma, 2009; 2016; Albuquerque y García, 2017a), permiten defender, aunque como una primicia, el carácter fronterizo de Myrtilis, sobre todo si se considera que los contextos de frontera son, generalmente, espacios privilegiados de interacción y de multiculturalidad. No disponemos de datos epigráficos que identifiquen inequívocamente un límite en este oppidum; sin embargo, la construcción de la muralla permite defender esta idea con un mínimo de seguridad, por lo menos en fechas anteriores al siglo II a.C. (cf. Hourcade et al., 2003; Palma, 2009; 2016). Además, el estudio de los contextos de consumo y de los materiales asociados permitirá, en los próximos años, avanzar en el análisis de las fronteras sociales (cf. Albuquerque y García, 2017b).

Por otra parte, los enfrentamientos con los lusitanos han centralizado la acción romana en territorios más septentrionales, lo que explica la iden- 
tificación de contextos arqueológicos más antiguos en el Tajo (Lisboa, Alcáçova de Santarém, Chões de Alpompé, etc.; cf. Str., 3,3,1; Arruda y Pimenta, 2014) y más tardíos (sc., último cuarto del siglo II a.C.) en el Algarve. Por otro lado, los hallazgos de Mértola pueden ser un reflejo de una penetración precoz hacia el interior (Fabião, 1987; Luís, 2003a; cf. Miguel, 2014).

Tras las Guerras Lusitanas, la prioridad de la presencia militar romana era la vigilancia y ocupación de los territorios conquistados, lo que se refleja en un poblamiento romano-republicano más intenso en el Algarve y, de acuerdo con los datos expuestos, en el Guadiana (una visión global en Salinas, 2010).

Se destaca en ese contexto una aparente necesidad de protección ante una amenaza inminente. Desde este punto de vista, Varrón desaconseja, a mediados del siglo I a.C., el cultivo en las zonas limítrofes de Lusitania (prope Lusitaniam), justificándolo con los pillajes que a menudo ocurrían (Var., R., 1.16.2, apud Cadiou y Moret, 2012, 39), lo que puede explicar la construcción de estructuras fortificadas como los castella, que garantizaban la protección y vigilancia de actividades económicas, sobre todo de la minería (Moret, 1999, 88; Cadiou y Moret, 2012, 39ss.). El yacimiento de Castelinho dos Mouros (Alcoutim) es el ejemplo más meridional de este tipo de ocupación (Gradim et al., 2014).

Sin embargo, se plantean dudas sobre su carácter (exclusivamente) militar y, por ende, fronterizo, considerándose que solo Castelo da Lousa cumple esa función (Fabião, 2002; Cadiou y Moret, 2012, con discusión de los aspectos más relevantes). Dichas estructuras, fortines y recintos-torre se distribuyen a lo largo del Anas y de sus principales afluentes (Alves, 2014). Estas construcciones en Lusitania son siempre de fundación romana-republicana, mayoritariamente del siglo I a.C., evidenciando técnicas constructivas y estructuras exteriores que las relacionarían con ocupaciones militares. Además, se ubican en pequeñas elevaciones (ibid., 398), en general sin ocupaciones anteriores, y su dispersión parece evidenciar la existencia de canales de penetración al interior coincidentes con los principales ríos y sus afluentes, y la explotación de recursos naturales asociados a estos territorios.

Esta necesidad de protección y vigilancia indica la existencia de relaciones menos pacíficas, o temos a quienes trabaja en los campos (¿riesgo de sublevaciones?) o a otros grupos y parece ser una estrategia de relativamente corta duración que puede estar relacionada con lo que el autor anónimo de Bellum Hispaniense señala en la Ulterior, sc., la construcción de torres que vigilaban amplios territorios fuera de las ciudades y protegían a las comunidades de las incursiones de "bárbaros" en c. 45 a.C. $(B H, 8,3$, apud Moret, 1999, 84-85).

Lamentablemente, aunque se conocen relativamente bien los patrones de asentamiento de estas estructuras, y se admite que forman parte de una estrategia de ocupación romana, son pocas las que han recibido intervenciones arqueológicas sistemáticas (cf. Gradim et al., 2014; Alves, 2014). La continuidad de esta investigación tendrá, seguramente, en cuenta la discusión de este aspecto, sobre todo en lo que respecta a una idea de protección y vigilancia de territorios fronterizos, más que de fronteras strictu sensu.

\section{CONCLUSIÓN: PERSPECTIVAS DE ESTUDIO}

Se concluyó hace tiempo que el Guadiana no fue en toda su extensión una frontera interprovincial, sino un punto de referencia geográfico eficaz en la transmisión de conocimientos sobre la Península Ibérica y las principales características de su territorio en algunos textos de la Antigüedad. No se podría exigir a los autores clásicos un grado de precisión de sus informaciones con respecto a los límites administrativos de cada ciudad o territorio mencionado en sus textos, sobre todo porque esa realidad sería inabarcable. Por otro lado, estas obras revelan un conocimiento cada vez más profundo de los confines occidentales del mundo habitado, e incluso fueron escritas por autores que estuvieron (Polibio, César, Plinio) o nacieron (Mela) en tierras peninsulares, a pesar de las disparidades entre la calidad, frabilidad y actualidad de las informaciones que transmitieron. De la lectura de estas obras se desprende una tendencia para describir territorios a partir de accidentes geográficos que ordenan el discurso o, en otras palabras, muestran la percepción de un receptor ausente. El texto de Polibio que abre esta contribución es un ejemplo claro en ese sentido y otros pueden, a su vez, indicar el uso de los ríos como elementos fronterizos o puntos estratégicos de defensa militar.

Los pueblos se describían dentro de esos límites geográficos, y a menudo es posible destacar en estas representaciones lo que sería la idea de frontera entre el mundo dominado por Roma y el de aquellos que eran catalogados según los estereotipos más co- 
munes ("bárbaros"; cf. Curchin, 1997, 70). Hemos preferido no entrar en este tema en este trabajo, puesto que justifica un estudio específico.

Los textos que mencionan batallas en las orillas de grandes ríos permiten tener una idea de cómo las líneas de agua pueden ser poderosos aliados en la defensa de territorios. Ello es especialmente evidente en textos de carácter militar como las obras de (y atribuidas a) Julio César, en las que sistemáticamente se hace referencia a los ríos y a las estrategias ofensivas y defensivas. Sin embargo, todo ello indica que este tipo de uso es reflejo de un momento histórico en el cual hay un conflicto entre grupos armados, cambiando en periodos de paz, esto es, cuando no hay una amenaza inminente. En otras palabras, la función de una frontera como barrera es un fenómeno que forma parte de circunstancias concretas que pueden tener un reflejo arqueológico como, p.ej., la construcción de estructuras como la de Castelo da Lousa (Mourão, Portugal), que aparentemente protege un punto de paso en el Anas.

Por tanto, las fuentes transmiten informaciones relevantes para la percepción territorial romana a partir de los primeros años de su presencia en la Península Ibérica y para su organización en términos muy generales. Las referencias textuales al Anas, si las comparamos, p.ej., con las del Baetis, indican una diferencia significativa en la importancia de cada uno de estos ríos, por lo menos para estos autores. De hecho, se conocen muchas operaciones militares en las orillas del Guadalquivir. Esta diferencia no significa que el Anas no fue importante, sobre todo si consideramos la ubicación estratégica de yacimientos como Castro Marim en la desembocadura del río y de Mértola en el límite del trecho navegable. Esta última ciudad se mantuvo activa, al contrario de la antigua Baesuris o de los castella, después del siglo I d.C., ubicándose en una importante red de vías romanas que la comunicaban con Pax Ivlia, Vipasca y otros puntos de la Península Ibérica (Lopes, 2006), lo que además queda evidenciado, posteriormente, por el abundante repertorio epigráfico paleocristiano identificado en esta villa del Alentejo.

Esta aparente falta de valoración del Bajo Guadiana (exceptuamos, evidentemente, la actual Mérida) y de las ciudades implantadas en sus orillas en los textos contrasta con la riqueza del registro arqueológico y epigráfico. De hecho, el desarrollo de programas de prospección puede enriquecer aún más este panorama, como se desprende de publi- caciones recientes (Freitas y Oliveira, 2007, sobre el Bajo Guadiana) y de las mencionadas campañas (García, Albuquerque y Palma, 2017). Por ello, se hace cada vez más necesario multiplicar este tipo de trabajos, sobre todo en el área de Mértola, complementados además con estudios de materiales arqueológicos que permitan conocer un poco mejor estas realidades y, por ende, desarrollar metodologías que permitan analizar los datos disponibles desde la perspectiva de la construcción de fronteras territoriales y simbólicas.

Desde el punto de vista metodológico, es necesario tratar la información desde una perspectiva comparativa. En primer lugar, destaca la comparación entre procesos de definición de fronteras en las fuentes escritas y en casos de estudio en la África precolonial (cf. el interesante caso de los hermanos Filenos en Sal. Jug., 74. 3; Ribichini, 1991). En segundo lugar, la comparación a escala regional permite definir con más precisión redes de poblamiento, relaciones de dependencia y jerarquización de los yacimientos, y destacar la función de asentamientos como Myrtilis, Baesuris y Alcoutim (cf. Bendala, 1987; Freitas y Oliveira, 2007). En tercer lugar, la comparación entre yacimientos cercanos ubicados en una y otra orilla de la cuenca baja del Guadiana es un punto de partida para definir la construcción de relaciones de pertenencia en torno al río. Por último, la comparación entre espacios de un mismo asentamiento, que permiten determinar estrategias de diferenciación social (fronteras simbólicas), principalmente en lo que respecta a contextos de consumo.

En lo que respecta al periodo tratado en este trabajo, el análisis de los modelos de ocupación y explotación del territorio es fundamental para comprender las funciones de estructuras como los castella y de otros núcleos habitacionales de menor escala, pero relacionados con el río. Este estudio, que esperamos desarrollar en otra ocasión, puede intentar explicar el abandono de poblados como Baesuris en el siglo I d.C. y, en general, de un sistema se poblamiento en altura, con excepción de Myrtilis, lo que no contradice la tendencia en otras áreas (cf. Polo y Villargordo, 2004, 171); al mismo tiempo, definir con rigor el papel de estos asentamientos en el proceso de romanización y el modo como reflejan adaptaciones al entorno social.

Obviamente, los datos disponibles, sobre todo para el estudio de las fronteras sociales, son escasos o no han recibido suficiente atención. Ello se 
debe a las nuevas preocupaciones sobre el patrimonio cultural en las regiones fronterizas, que a su vez imponen nuevas cuestiones sobre los yacimientos y materiales identificados. Ello anima a profundizar, p.ej., en el análisis de los contextos de consumo y de los datos asociados (alimentos de origen animal y vegetal disponibles, importaciones, producción local, características ambientales de un determinado periodo, etc.), y a ver los territorios fronterizos como sistemas con identidades propias y no únicamente como espacios periféricos y de separación (Albuquerque, 2017; Albuquerque y García, 2017b).

En ese sentido, cabe destacar, como se ha hecho en otra ocasión, algunos problemas que se plantean a la investigación arqueológica de estos paisajes transfronterizos (García, Del Espino y Albuquerque, 2017). Quizás en un futuro estudio que valore la historia del poblamiento a lo largo del antiguo Anas y su patrimonio nos permita tratar la eurorregión Alentejo - Algarve - Andalucía en un marco común y unificado que transmita, a través de la investigación histórica y arqueológica, la complicidad y la singularidad de los territorios fronterizos.

\section{BiBLIOGRAFÍA}

Las abreviaturas de las fuentes clásicas siguen el Greek - English Lexicon (Liddell y Scott) y el Oxford Latin Dictionary, a excepción del Papiro de Artemidoro (= Pap. Art.).

Alarcão, J. (2010), “A costa portuguesa em Artemidoro”, Revista Portuguesa de Arqueologia, 13, $107-123$.

Alarcão, J.; Gorges, J.-G.; Mantas, V.G.; Salinas, M.; Sillières, P. y Tranoy, A. (1990), "Appendice : Propositions pour un nouveau tracé des limites de la Lusitanie romaine", Les villes de Lusitanie Romaine (Gorges, J.-G. ed.), Paris y Bordeaux, 319-328.

Albuquerque, P. (2017), "O Guadiana como fronteira? Notas para um projecto de investigação", Ophiussa, 1, 69-78.

Albuquerque, P. y García Fernández, F.J. (2017), "Mértola entre el Bronce Final y el inicio de la presencia romana: problemas y perspectivas de investigación”, Habis, 48, 7-30.

Albuquerque, P. y García Fernández, F.J. (2017b), "Sobre o conceito de fronteira: o Guadiana numa perspectiva arqueológica”, Territorios Comparados: los valles del Guadalquivir, el Tajo y el Guadiana en Época Tartésica (Celestino
Pérez, S. y Rodríguez González, E. eds.), Anejos de Archivo Español de Arqueología, LXXX, 175-182.

Alves, C. (2014), "Os Castella do Baixo-Alentejo. O caso do Monte Manuel Galo", Cira Arqueológica, 3, 385-402

Ariño, E. y Gurt, J.M. (1994), “Catastros romanos en el entorno de Avgusta Emerita. Fuentes literarias y documentación arqueológica”, Les campagnes de Lusitanie romaine : occupation du sol et habitats (Gorges, J.-G. y Salinas de Frías, M. eds.), Madrid, Salamanca, 45-66.

Arruda, A.M. (1988), "Nota acerca da ocupação romana republicana do Castelo de Castro Marim”. Actas do $5^{\circ}$ Congresso sobre o Algarve (Montechoro, 1988). Silves, 13-17.

Arruda, A.M. (1999-2000), Los fenicios en Portugal, Cuadernos de Arqueología Mediterránea, 5-6.

Arruda, A.M. (2003). "Escavações arqueológicas no Castelo de Castro Marim: balanço e perspectivas”, Xelb, 4, 69-88.

Arruda, A.M. y Pereira, C. (2008), “As ocupações antigas e modernas do Forte de São Sebastião, Castro Marim”, Xelb, 8, 365-395.

Barros, P. (2008), "Mértola durante os séculos VI e V a.C.", Sidereum Ana I: El río Guadiana en época post-orientalizante (Jiménez Ávila, J. ed.), Anejos de Archivo Español de Arqueologia, 46, Mérida, 399-414.

Bendala Galán, M. (1987), “Ab Ostio fluminis Anae”, Cuadernos de Prehistoria y Arqueología de la Universidad Autónoma de Madrid, 13-14, 129-139.

Bernardes, J.; Fernández Sutilo, L.; Campos Carrasco, J. y Pereira, C. (2014), "El mundo funerario del extremo suroccidental de Hispania a través de dos ciudades: Ossonoba versus Onoba”, Onoba, 2, 127-147.

Blánquez Pérez, J. (2000), "En torno al problema de las rutas terrestres en el interior de la Península Ibérica", Pyrenae, 22-23, 173-180

Blot, M.L.P. (2004), "Circulação aquática e o papel dos portos flúvio - estuarinos nos contactos da Lusitânia Romana. O caso do litoral e dos rios de Portugal.”, V Mesa Redonda Internacional sobre Lusitania romana: las comunicaciones (Gorges, J.-G.; Cerrillo, E. y Nogales, T. eds.), Cáceres, 465-480.

Cadiou, F. y Moret, P. (2012), "Rome et la frontière hispanique à l'époque républicaine $\left(\mathrm{II}^{\mathrm{e}}-\mathrm{I}^{\mathrm{er}} \mathrm{s}\right.$. Av. 
J.-C.)”, Les sociétés méditerrannéennes face au risque (Velud, C. ed.), Paris, 21 - 44.

Campbell, B. (2012), Rivers and the power of Ancient Rome. Chapel Hill.

Canto, A. M. (1989), "Colonia Iulia Augusta Emerita: consideraciones en torno a su fundación y territorio", Gerión 7, 149-206

Canto, A.M. (1994), Epigrafía Romana de la Beturia Céltica (=ERBC), Madrid.

Carneiro, A.M. (2010), Itinerários Romanos do Alentejo: uma releitura de "As Grandes Vias da Lusitânia - O Itinerário de Antonino Pio" de Mário Saa, cinquenta anos depois, Lisboa.

Chaves, F. y García Vargas, E. (1994), "Gadir y el comercio atlántico a través de las cecas occidentales de la Ulterior", Arqueología en el entorno del Bajo Guadiana, Actas del Encuentro Internacional de Arqueología del suroeste (Campos Carrasco, J.M.; Pérez Macías, J.A. y Gómez, F. coords.), Huelva, 375-392.

Chic García, G. (2005), "El comercio de la Bética altoimperial”, Habis, 36, 313-332.

Corzo Sánchez, R. y San Gil, M.T. (1992), Las vías romanas de Andalucía. Sevilla.

Cruz Andreotti, G. (2006), "Polibio y la integración histórico - geográfica de la Península Ibérica”, La invención de una geografía de la Península Ibérica, I, La época republicana (Cruz Andreotti, G.; Le Roux P. y Moret, P. eds.), Málaga, Madrid, 77-96.

Cruz Andreotti, G.; García Quintela, M.V. y Gómez Espelosín, F.J. (2009), Estrabón: Geografía de Iberia, Madrid.

Curchin, L.A. (1997), "Roman Frontier concepts in the Spanish Interior", Roman Frontier Studies 1995 (Waateringe, W.G.-v.; Beek, B.L.van; Willems W.J.H. y Wynia, S.L. eds.) 67-71.

D’Encarnação, J. (1984), Inscrições Romanas do Conventus Pacencis (= IRCP). Coimbra.

Dias, M.M.A. y Coelho, L. (1995-97), "Endovélico: Caracterização social da romanidade dos cultuantes e do seu santuário (S. Miguel da Mota, Terena, Alandroal)", O Arqueólogo Português, série IV, 13-15, 233-265.

Fabião, C. (2002), "Os chamados Castella do Sudoeste. Arquitectura, cronologia e funções”, Archivo Español de Arqueología, 75, 177-193.

Fabião, C. (2009), “A dimensão atlântica da Lusitânia: periferia ou charneira no império romano?", Lusitânia Romana - entre o mito e a realidade. Cascais, 53-74.
Faria, A.M. (1995), "Plínio - o - Velho e os estatutos das cidades privilegiadas hispano - romanas localizadas no actual território português”, $V i$ pasca, 4, 89-99.

Faria, A.M. (2001), Oppida ueteris Latii Ebora, quod item Liberalitas Iulia, et Myrtilis ac Salacia (Plin, nat. 4.117), Vipasca, 10, 71-82.

Faria, A.M. (2009), "Artemidoro entre os Salakeinoi?”, Revista Portuguesa de Arqueologia, 12 (1), 115-125.

Favory, F. (2005), "Limites et territoires d'après le corpus gromatique", Caesarodunum 39, 153195

Francisco Martín, J. (1978), “Cuestiones en torno al límite occidental de la Bética", Actas del I Congreso de Historia de Andalucía, diciembre de 1976, Fuentes y Metodología. Andalucía en la Antigüedad, Córdoba, 179-185.

García Fernández, F.J. (2003), Los turdetanos en la historia: análisis de los testimonios literarios grecolatinos. Écija.

García Fernández, F.J.; Albuquerque, P. y Palma, M. F. F. (2017), "Mértola na Idade do Ferro: primeiros resultados de dois projectos de investigação”, Actas do II Congresso da Associação dos Arqueólogos Portugueses, Arqueologia em Portugal 2017: Estado da questão. Lisboa, 161-170.

García Fernández, F.J.; Del Espino Hidalgo, B. y Albuquerque, P. (2017), Paisajes transfronterizos como objeto de estudio: interés, oportunidad y complejidad en el caso de la eurorregión Alentejo - Algarve - Andalucía, en Colóquio Ibérico de Paisagem - $O$ estudo e a construção da paisagem como problema metodológico. Lisboa, 119 - 140.

García Iglesias, L. (1972), "El Guadiana y los límites comunes de la Bética y Lusitania”, Hispania Antiqua, 2, 165-178.

Gargola, D. (2005), "Hyginus Gromaticus and Frontinus on the installation of Limites: Ritual, Law, and Legitimacy”, Caesarodunum, $39,125-152$

González, J. (2004), “Límites entre provincias, ciudades y territorios", Epigrafia di confine, confine dell'epigrafia: Atti del Colloquio AIEGL, Borghesi, 2003 (Angeli Bertinelli, M.G. y Donati, A. eds.), Faenza, 49-64.

Gradim, A.; Grabherr, G; Kainrath, B.; Teichner, F. (2014), "O Castelinho dos Mouros (Alcoutim): um edifício republicano do Baixo Guadiana, no 
período da fundação da Lusitânia Romana”, Los paisajes agrários de la Romanización, arquitectura y explotación del territorio II, Anejos de Archivo Español de Arqueología, LXX, 46-64.

Guerra, A. (1995), Plínio - o - Velho e a Lusitânia. Lisboa.

Guerra, A. (2007), "Reflexões em torno de alguns elementos da toponomástica do Extremo Ocidente peninsular", Onomástica gallega con especial consideración da situación prerromana. Actas do Primeiro Colóquio de Trier, 19 e 20 de Maio de 2006 (Kremer, D. ed.), Santiago de Compostela, 113-134.

Hourcade, D.; Lopes, V. y Labarthe, J.M. (2003), "Mértola: La muraille de l'âge du Fer", Revista Portuguesa de Arqueologia, 6 (1), 75-210.

IRCP: D’Encarnação 1984.

Isaac, B. (1998), "The meaning of Limes and Limitanei in Ancient Sources", The Near East under Roman Rule: Selected Papers, Leiden, New York, Köln, 349-387.

Le Roux, P. (1994), "Cités et territoires en Hispanie: l'épigraphie des limites". Mélanges de la Casa de Velázquez, 30 (1), 37-51.

Le Roux, P. (2010), "Les colonies et l'institution de la province romaine de Lusitanie", Naissance de la Lusitanie romaine (Ier av. - Ier ap. J.- C.): VIIe Table Ronde Internationale sur la Lusitanie romaine (Toulouse, 8-9 novembre 2007) $=$ Origen de la Lusitania Romana (siglos I a.C. - I d.C.): VII Mesa Redonda International sobre la Lusitania Romana (Toulouse, 8-9 novembre 2007) (Gorges J.-G. y Nogales Basarrate, T. eds.), Toulouse, Mérida, 69-91.

Lopes, V. (2006), "O território de Mértola e as vias de comunicação no período romano", $A c$ tas das I Jornadas "As vías do Algarve: da Época Romana à Actualidade”. São Brás de Alportel, 46-53.

Luís, L. (2003a), As cerâmicas campanienses de Mértola. Trabalhos de Arqueologia, 27. Lisboa.

Luís, L. (2003b), “As ânforas republicanas de Matafilhos (Mértola), Revista Portuguesa de Arqueologia, 6 (2), 363-382.

Marcos, S. (2011), "Espace géographique, espace politique: la frontière provinciale lusitanienne, une limite déterminante?", Roma generadora de identidades. La experiencia hispana (A. Caballos Rufino y S. Lefebvre, eds.) Madrid, Se- villa, 171-184.

Mayer, M. (2004), "Epigrafía sin fronteras. Una reflexión acompañada de algunas notas sobre documentos epigráficos de confines”, Epigrafia di confine, confine dell'epigrafia. Atti del Colloquio AIEGL - Borghesi 2003, (Angeli Bertinelli, M.G. y Donati, A. eds.), Faenza, 7-22.

Miguel, L. (2014), “A intervenção arqueológica no Monte das Covas 3 (S. Matias, Beja). Os contextos romanos de época republicana, $4^{\circ}$ Colóquio de Arqueologia do Alqueva: o Plano de Rega (2002 - 2010), Memórias d'Odiana, $2^{\mathrm{a}}$ Série, 14 , Évora, 280-283.

Monsalud, M. de (1897), "Nuevas inscripciones romanas y visigóticas”, Boletín de la Real Academia de la Historia 30, 415-422.

Moret, P. (1999), "Casas fuertes romanas en la Bética y la Lusitania”, Économie et territoire en Lusitanie Romaine (Gorges J.-G. y Rodríguez Martín, F.G. eds.), Madrid, 55-89.

Morillo, A. y Salido, J. (2010), "El aprovisionamiento del ejército romano en Hispania. Transporte, almacenaje y redistribución", Militares y civiles en la antigua Roma: dos mundos diferentes, dos mundos unidos (Palao Vicente, J. coord.), Salamanca, 135-164.

Navarro, M. y Ramírez, J.L. coords. (2003), Atlas antroponímico de la Lusitania Romana. Mérida - Bordeaux.

Oliveira, C.F.P. y Freitas, V.T. (2007), “A Idade do Ferro no Baixo Guadiana”, IV Congresso de Arqueologia Peninsular, Faro, 409-418.

Palma, M. a F. (2009), Arqueologia urbana na biblioteca municipal de Mértola (Portugal): contributos para a história local. Trabajo de Fin de Máster, Universidad de Huelva, inédito.

Palma, M. F. (2016), “Arqueologia urbana na área de expansão da Biblioteca de Mértola”, Arqueologia Medieval, 13, 5-16.

Palma, M. ${ }^{a}$ F., coord. (2012), Carta arqueológica do Concelho de Mértola, Mértola.

Parodi Álvarez, M.J. (2014), "Los Ríos Occidentales de la Hispania romana en las fuentes clásicas. Una aproximación”, Onoba, 2, 179-189.

Pastor Muñoz, M. (1978), "La Península Ibérica en Marciano de Heraclea”. Hispania Antiqua, 8, 89-128.

Pastor Muñoz, M. (2004), "Vías de comunicación y relaciones comerciales entre Bética y Lusitania”, $V$ Mesa Redonda Internacional sobre Lusitania Romana: Las comunicaciones (Geor- 
ges, J.-G.; Cerrillo E. y Nogales Basarrate, T. eds.), Madrid, 195-222.

Pereira, C. (2014), As necrópoles romanas do Algarve. Tesis doctoral, inédita.

Pereira, C. y Albuquerque, P. (2018), "Os enterramentos infantis em ânfora em época romana: da prática ao rito", Spal 27.1, 89 - 118.

Pérez Vilatela, L. (2000), Lusitania: Historia y Etnología. Madrid.

Picón García, V.; Agudo Cubas, R. M.a (2008), Suetonio: Vidas de los Doce Césares, 2 vols., Madrid.

Polo Cutando, C. y Villargordo Ros, C. (2004), "Del poblado fortificado al asentamiento en llano: La evolución de los asentamientos rurales en el Sistema Ibérico Central (s. III a.C.-I d.C.)”, Torres, Atalayas y casas fortificadas. Explotación y control del territorio en Hispania (S. III a. de C. - S. I d. de C.) (Moret P. y Chapa, T. eds.), Madrid, 13-29.

Ramírez Sábada, J.L. (1994), "La Baeturia céltica y los límites con Lusitania", Historia Antigua: Actas del II Congreso de Historia de Andalucía (Córdoba, 1991), Córdoba, 345-354.

Ramírez Sádaba, J.L. (1993), "Dos "Termini augustales" del "Territorium emeritense": Uno de Valencia del Ventoso y otro de Montemolín”, Veleia, 10, 301-306.

Rankov, B. (2005), "Do Rivers make good frontiers?", Limes XIX: Proceedings of the XIX ${ }^{\text {th }}$ International Congress of Roman Frontier Studies. Pécs, Hungary, September 2003 (Visy, Z. ed.), Pécs, 175-181.

Ribichini, S. (1991), "I fratelli Fileni e i confini del territorio cartaginese", Atti del II Congreso Internazionali di Studi Fenici i Punici, vol.1, Roma, 343-400.

Roldán Hervás, J.M. (1975), Itineraria Hispana: Fuentes Antiguas para el estudio de las vías romanas en la Península Ibérica. Valladolid.

Ruiz Acevedo, J.M. y Campos Carrasco, J.M. (2009), "El litoral onubense y algarveño en el Papiro de Artemidoro: una nueva interpretación”, Habis, 40, 89-107.

Sáez Fernández, P. (1990), "Estudio sobre una inscripción catastral colindante con Lacimurga", Habis, 21, 205-227.

Salinas de Frías, M. (2010), "La provincia Ulterior entre Décimo Bruto y Augusto: los precedentes republicanos de la Lusitania imperial. Los gobiernos provinciales", Naissance de la Lusi- tanie romaine (Ier av. - Ier ap. J.- C.): VIIe Table Ronde Internationale sur la Lusitanie romaine (Toulouse, 8-9 novembre 2007) = Origen de la Lusitania Romana (siglos I a.C. - I d.C.): VII Mesa Redonda International sobre la Lusitania Romana (Toulouse, 8-9 novembre 2007) (Gorges, J.-G. y Nogales, T. eds.), Toulouse, 39-68.

Sayas, J.J. (1989), "Colonización y municipalización bajo César y Augusto: Bética y Lusitania”, Aspectos de la colonización y municipalización de España, Mérida, 33-70.

Sillières, M.P. (1982), "Centuration et voie romaine au Sud de Mérida: contribution à la délimitation de la Bétique et de la Lusitanie”, Mélanges de la Casa de Velázquez, 18 (1), 437-448.

Sillières, P. (1990), "Voies romaines et limites de provinces et de cités en Lusitanie”, Les villes de la Lusitanie romaine, Paris, 77-88.

Simplício, C.; Lopes, V. y Barros, P. (2003), "O Porto de Myrtilis”, Actas das IV Jornadas de Arqueología Subacuática: Reunión Internacional "Puertos fluviales antiguos: Ciudad, desarrollo e infraestructuras», Valencia, 35-48.

Sorìa, V. y Palma, M. F. (2017), "A cerâmica de tipo Kuass em Mértola (Portugal). As escavações da Biblioteca Municipal”, Archivo Español de Arqueología, 90, 77-96.

Talbert, R.J.A. (2004), "Rome's provinces as framework for world - view", Roman rule and civic life: local and regional perspectives. Proceedings of the fourth Workshop of the International network impact of Empire (Roman Empire, c. 200 b.C. - A.D. 476 (De Ligt, L.; Hemelrijk, E.A. y Singor, H.W. eds.), Amsterdam, 21-37.

Teixeira, S.M. (2015), Cultos e cultuantes no sul do território actualmente português em época romana (sécs. I aC. - III d.C.): uma aproximação à sociologia das religiões. Trabajo de Fin de Máster, inédito.

Thulin, C. (1913), Corpus Agrimensorum Romanorum. Leipzig.

TIR = AAVV (1995), Tabvla Imperii Romani, Hoja J - 29: Lisboa. Emerita - Scallabis Pax Ivlia-Gades. Madrid.

Viegas, C. (2006), “A ocupação romana de Castro Marim”, Xelb, 6, 241-260.

Viegas, C. (2011), A ocupação romana do Algarve. Estudo do povoamento e economia do Algarve central e oriental no período romano. 
Lisboa.

Villar, F. (2014), Indoeuropeos, iberos, vascos y sus parientes: estratigrafía y cronología de las poblaciones prehistóricas. Salamanca.

Whittaker, C.R. (2000), "Frontiers", The Cambridge Ancient History, XI, The High Empire, $A D 70$ - 192, (Bowman, A.K.; Garnsey, P. y Rathbone, D. eds.), $2^{\mathrm{a}}$ ed., Cambridge, 293-319.

Whittaker, C.R. (2002) "Mental maps: seeing like a Roman. Thinking like a Lawyer: essays on legal history and general history for John Crook in his Eightieth birthday (McKechnie, P. ed.), Leiden [etc.], 81-112. 
